\title{
Gender priming in Italian
}

\author{
ELIZABETH BATES \\ University of California, San Diego, La Jolla, Califormia \\ ANTONELLA DEVESCOVI \\ University of Rome "La Sapienza," Rome, Italy \\ ARTURO HERNANDEZ \\ University of California, San Diego, La Jolla, Califormia \\ and \\ LUIGI PIZZAMIGLIO \\ University of Rome "La Sapienza," Clinica Santa Lucia, Rome, Italy
}

\begin{abstract}
The goals of the present study were (1) to determine whether grammatical gender on a noun modifier can prime recognition of the following noun, (2) to determine whether the priming effect involves facilitation, inhibition, or both, and (3) to compare performance across three different tasks that vary in the degree to which explicit attention to gender is required, including word repetition, gender monitoring, and grammaticality judgment. Results showed a clear effect of gender priming, involving both facilitation and inhibition. Priming was observed whether or not the subjects' attention was directed to gender per se. Results suggest that gender priming involves a combination of controlled postlexical processing and automatic prelexical processing. Implications for different models of lexical access are discussed, with special reference to modular versus interactive-activation theories.
\end{abstract}

\section{Why Grammatical Priming?}

The issue of whether gender can be a useful prime in lexical access is a particular example of a more general problem: How can context influence the nature and timing of information access during lexical processing? The answer to this question has consequences for theories of language comprehension, including the contrast between modularity and interactive models of lexical access (for reviews, see Balota, 1992, Frauenfelder \& Tyler, 1987 , and Levelt, 1992).

If grammatical gender does contribute to word recognition, then it can be said to constitute an example of grammatical priming. Two earlier studies provided evidence for faster lexical decisions when the prime and target are preceded by a syntactically appropriate context (Goodman, McClelland, \& Gibbs, 1981, in a study of English) or when they were preceded by an appropriate preposition (Lukatela, Kostić, Feldman, \& Turvey, 1983, in a study of Serbo-Croatian). However, subsequent experiments in English by Seidenberg, Water, Sander, and Langer (1984), Tyler and Wessels (1983), West and Stanovich (1982, 1986), and Wright and Garrett (1984) have shown

This research was supported by NIDCD Grant PHS DC00216 to E.B. and by the Clinica Santa Lucia in Rome. The authors would like to thank Larry Juarez and Robert Buffington for technical assistance and Meiti Opie for assistance in manuscript preparation. Correspondence should be addressed to E. Bates, Center for Research in Language 0526, University of California, San Diego, La Jolla, CA 92093 0526 . that grammatical priming is relatively weak. Furthermore, they suggest that grammatical influences on lexical processing are inhibitory in nature and probably occur at some point shortly after the target word is recognized (i.e., they are postlexical effects). For reasons that we will outline in more detail below, this may also mean that grammatical priming is conscious and strategic.

In a summary of the literature on priming in spoken word recognition, Tanenhaus and Lucas (1987) conclude, "On the basis of the evidence reviewed ... it seems likely that syntactic context does not influence prelexical processing" (p. 223). They speculate that this is the case because syntactic context has relatively little to offer:

Feedback from a syntactic context to words that belong to possible or even expected syntactic categories will do little to reduce the potential number of lexical candidates.... Thus it would appear that syntactic to lexical feedback would generally be of limited utility. (Tanenhaus \& Lucas, 1987, p. 224)

This conclusion may be valid for English, a language with relatively little inflectional morphology, but the argument is less convincing for richly inflected languages in which agreement morphology can provide powerful constraints on lexical access. In fact, a number of recent studies conducted in other languages have forced a reconsideration of grammatical priming in lexical access, although the nature and locus of the effect are still unclear. Using a combination of gating and lexical decision, Grosjean, Dommergues, Cornu, Guillelmon, and Besson (1994) have shown that gender marking affects word 
recognition in French, with earlier recognition points in gating and faster reaction times in lexical decision for nouns that are preceded by an article that is correctly marked for gender. The difference between performance with and without an article suggests that the effect may be due to facilitation. Using a cross-modal lexical decision paradigm, Friederici and Kilborn (1989; see also Kilborn \& Friederici, in press) have demonstrated a combination of syntactic and morphological priming in German, but these effects appear to be inhibitory in nature (i.e., reaction times are slower following a grammatical violation, compared with control conditions).

To summarize, evidence supporting an effect of grammatical context on lexical recognition is still relatively slim, and most of the effects that have been reported to date can be interpreted as postlexical and inhibitory in nature (a point to which we shall return shortly). However, it must be noted that most of these studies were not optimally designed to disentangle the relative contributions of facilitation and inhibition. For this reason, we have chosen to focus on the role of gender marking in Italian, a language whose characteristics (see below) provide an ideal linguistic milieu to approach this issue systematically and to overcome important methodological problems.

\section{Why Gender?}

Grammatical gender is of interest because it is a pervasive phenomenon in many of the world's languages, and yet there are relatively few studies investigating its role in lexical and grammatical processing. Developmental studies have shown that gender is acquired relatively early by young children, at least for those parts of the language in which it is clearly marked (e.g., Devescovi, D'Amico, Smith, Mimica, \& Bates, 1994; MacWhinney, 1978; Orsolini, 1993; Pizzuto \& Caselli, 1992). Other studies have shown that adult native speakers are able to recognize and classify words according to gender quickly and without a great deal of effort (cf. Bates, Devescovi, Pizzamiglio, D'Amico, \& Hernandez, 1995; Brooks, Braine, Catalano, Brody, \& Sudhalter, 1993; Burani, 1992; Cassidy \& Kelly, 1991; Colé \& Segui, 1994; Deutsch \& Wijnen, 1985; Radeau, Mousty, \& Bertelson, 1989; see also unpublished studies reported in Brown, Senft, \& Wheeldon, 1993). They can use gender information as a cue to semantic roles (i.e., "who did what to whom"; (Devescovi et al., 1994; Kail, 1989), and they are sensitive to errors of gender marking in real-time language comprehension (e.g., Friederici \& Schriefers, 1993; Jarema \& Friederici, 1994). In other words, we know that gender marking is an option favored by many of the world's languages, and we know that native speakers can acquire and process gender with efficiency. Nevertheless, we still do not really understand why so many of the world's languages persist in the use of a costly linguistic device that serves no obvious communicative function.

One possible explanation for the pervasiveness and persistence of gender may be that it does serve a com- municative function, although that function has little or nothing to do with sexuality (Bates et al., 1995). In contrast with other aspects of inflectional morphology (i.e., case, number, person, tense, and aspect), gender is an inherent property of nouns that can be retrieved at the moment of lexical access, for words presented out of context. In addition, the continued marking of gender within and across sentences may help the listener to keep track of several different referents in a complex discourse.

Some evidence in favor of this view comes from Kilborn (1987), who showed that German listeners have an advantage over English subjects in a word-monitoring task in which words must be identified in syntactically well-formed but semantically anomalous prose (e.g., "Colorless green IDEAS sleep furiously"). In the same vein, Grosjean et al. have shown that gender marking on the article serves as a powerful cue to recognition of a subsequent noun. The present study will replicate and extend the Grosjean et al. findings for French, taking advantage of some properties of Italian that permit further clarification of the processes that underlie gender priming.

\section{Properties of Gender in Italian}

In Italian, there are only two genders, masculine and feminine (in contrast, e.g., with the three genders of German and Russian, or the six genders of Swahili; see Grosjean et al., 1994). Gender is an inherent, contextindependent property of every Italian noun, and gender agreement must be marked on almost all modifiers (i.e., articles, determiners, and adjectives; numerals are not marked for gender), on all coreferential pronouns (including full pronouns and clitics), and on the past participle of the verb. There are no unmarked or zero noun forms in Italian. Except for a small number of foreign loan words (e.g., bar), all Italian nouns end in a vowel, and gender and number are marked together on that final vowel. For the great majority of nouns (and for most agreeing adjectives), masculine forms end in $o$ in the singular and $i$ in the plural, and feminine forms end in $a$ in the singular and $e$ in the plural. We will refer to these as phonologically transparent items. For a minority of both masculine and feminine word types (and some agreeing adjectives), the final vowel is $e$ in the singular and $i$ in the plural. Because gender cannot be recovered from surface form alone on words within this class, we will refer to them as phonologically opaque. Note that such nouns are not ambiguous for gender (although adjectives that end in $e$ are ambiguous unless one knows the identity of the noun they modify; see below); gender is a fixed property of every noun, known by every native speaker and presumably available as soon as that noun is identified, whether or not gender is transparently marked on the final vowel (i.e., whether nor not the noun "wears its gender on its sleeve"). Both transparent and opaque word types will be used in the present study to investigate whether this dimension affects performance by native speakers in either of our tasks.

In Italian (like all of the gender-marked languages in the world), the relationship between semantic and gram- 
matical gender is arbitrary in most cases. Furthermore, Bates et al. (1995) have shown that semantic gender has no measurable effect on lexical access or gender classification when words are presented out of context (where semantic gender is defined as the masculine or feminine identity of the animate beings to which a word refers). Nevertheless, in order to avoid any possible conflicts between grammatical and semantic gender, we will restrict ourselves to words designating inanimate referents (i.e., items whose referents are not inherently masculine or feminine).

\section{Choice of Tasks}

When approaching a relatively new domain of psycholinguistic inquiry, it is useful to look for information that is relatively independent of specific techniques. In the present study, we will use three different techniques to study the effects of adjective gender on processing of a subsequent noun.

The first task is alternatively called word repetition, auditory naming, or single-word shadowing (for some examples of priming studies using this technique in context, see Herron, 1994; Liu, Bates, Powell, \& Wulfeck, in press; Slowiaczek, 1994). Subjects are simply asked to repeat the second word in a series of word pairs, where the first word is an adjective serving as the grammatical context or "prime," and the second word is a noun that serves as the target. This task is important for our purposes here because it requires no metalinguistic decision and no attention whatsoever to gender or its morphological markers. Word repetition has been used in a previous study of gender and lexical access for individual words in Italian (Bates et al., 1995) and can bring important contributions to the understanding of the nature of a possible gender priming.

The second task has been called gender monitoring and/or gender classification. Subjects are asked to listen to a series of adjective-noun pairs (the same stimuli used in the word repetition task) and to press one of two buttons indicating whether the noun target has feminine or masculine gender. Variants of this task have been used in previous studies of gender processing for isolated words (Bates et al., 1995; Radeau et al., 1989); our own results to date suggest that performance may change when subjects are asked to focus explicitly and consciously on the gender dimension. In particular, repetition of nouns out of context is not affected by phonological transparency of gender monitoring, but gender monitoring of the same nouns out of context is significantly and robustly affected by the presence or absence of a transparent gender cue (i.e., slower performance for both masculine and feminine nouns that end with the phonologically opaque vowel $e$ ).

In the third task, called grammaticality judgment or error detection, subjects are not asked to focus explicitly on noun gender, but they are asked to decide whether an adjective-noun sequence is grammatical or ungrammatical. Since gender is the only morphological dimension that we will use to create grammatical and ungrammati- cal pairs, this constitutes an indirect way to induce conscious attentive processing of the gender dimension. Hence, gender monitoring and grammaticality judgment should favor a more strategic, controlled mode of gender processing, whereas word repetition is more likely to tap into automatic effects (more on this below). In addition, the grammaticality judgment task will help us to determine whether awareness of the gender mismatch precedes or follows other priming effects. If we can show that detection of a gender mismatch is faster than word repetition and/or gender monitoring, then we would have evidence for the idea that conscious awareness of the mismatch "causes" a relative slowing in the other two tasks. Alternatively, if it turns out to be the case that grammaticality judgment is slower than word repetition and/or gender monitoring, then it is less likely (albeit not impossible) that priming effects in the latter two tasks are "caused" by conscious awareness of an error. This brings us to a final issue, revolving around the point in processing where gender and other morphological cues may have their effect.

\section{When Does Word Recognition Take Place?}

We have proposed that gender and gender agreement are pervasive phenomena in many of the world's languages because they make it easier for listeners to recognize words and track coindexed forms across a complex discourse (see also Bates et al., 1995; Grosjean et al., 1994; Kilborn, 1987). In other words, we are claiming that gender facilitates lexical access "in the real world." The three experiments presented below would be of little relevance to this claim if our effects reflect nothing more than experiment-specific strategies that emerge in a strange laboratory world in which gender agreement is violated (something that rarely occurs in spoken or written Italian). How can we tell the difference? This concern brings us directly into a complex tangle of theoretical and methodological issues that must be confronted in any study of context effects on lexical access, revolving around the hypothetical border between prelexical processes (events that are responsible for word recognition, defined here to include contextual factors prior to presentation of the word and to intralexical processes that take place entirely within the lexicon) and postlexical processes (events that take place after a word has been recognized, including but not limited to experimentspecific strategies).

Table 1 summarizes a list of properties that characterize what we shall call the standard two-stage model of lexical access (adapted from Hernandez, Bates, \& Avila, in press). Although we have not seen this complete list of claims in any single paper on lexical access, various aspects of this two-stage model can be found throughout the lexical-access literature (e.g., Chiarello, 1991; Neely, 1991; Swinney, 1979; see papers in Frauenfelder \& Tyler, 1987, and Gernsbacher, 1994). In most variants of the standard model, word recognition is viewed as a modular bottom-up process in which lexical items are activated by two sources of information: perceptual in- 
Table 1

Priming Effects on Word Recognition: Theoretical Assumptions and Empirical Tests of the Standard Two-Stage Model

\begin{tabular}{|c|c|c|}
\hline Manipulation & Assumption & $\begin{array}{l}\text { Predicted Outcome } \\
\text { for Priming Effects }\end{array}$ \\
\hline Reaction time & $\begin{array}{l}\text { Automatic }=\text { fast } \\
\text { Controlled }=\text { slow }\end{array}$ & $\begin{array}{l}\text { Priming at short } S O A s=\text { automatic } \\
\text { Priming at long SOAs }=\text { controlled }\end{array}$ \\
\hline $\begin{array}{l}\text { Expectations/ } \\
\text { attention }\end{array}$ & $\begin{array}{l}\text { Automatic }=\text { unconscious, no attention required } \\
\text { Controlled }=\text { conscious, attention required }\end{array}$ & $\begin{array}{l}\text { Priming without attention = automatic } \\
\text { Priming with attention }=\text { controlled }\end{array}$ \\
\hline \multirow[t]{2}{*}{ Direction of priming } & Automatic $=$ facilitation only & $\begin{array}{l}\text { Priming faster than neutral } \\
\text { baseline = automatic }\end{array}$ \\
\hline & Controlled $=$ facilitation and inhibition & $\begin{array}{l}\text { Priming slower than neutral } \\
\text { baseline = controlled }\end{array}$ \\
\hline Speeded response & Insufficient time for strategies to apply & Priming only for automatic \\
\hline $\begin{array}{l}\text { Perceptual } \\
\text { degradation }\end{array}$ & $\begin{array}{l}\text { Allows spreading activation to build } \\
\text { within the lexicon }\end{array}$ & $\begin{array}{l}\text { Increased priming only for } \\
\text { automatic processes }\end{array}$ \\
\hline Delayed response & Allows strategies to apply & $\begin{array}{l}\text { Increased priming only for } \\
\text { controlled processes }\end{array}$ \\
\hline
\end{tabular}

formation from the incoming word (orthographic or phonological), and spreading activation within the lexicon (which may include both phonological and semantic information from preceding words that are still active). These events are classified as "prelexical," in that they take place before the word is recognized and contribute to its recognition. Other sources of information have their effects only after the lexical item has been accessed in a second, "postlexical" stage that may include selection of contextually appropriate candidates, inhibition of inappropriate candidates, and integration of the chosen item into a larger contextual frame. As noted in the above quote by Tanenhaus and Lucas (1987), this would include grammatical priming. The language of the two-stage model is so pervasive in the field that it is used even by those who are critical of it (e.g., Marslen-Wilson \& Tyler, 1980; Tabossi \& Zardon, 1993), and it has shaped methodological decisions and operational definitions in hundreds of experiments.

Building on a long-standing distinction between automatic and controlled processing (Posner \& Snyder, 1975; Shiffrin \& Schneider, 1977), it is generally argued that prelexical processes are automatic, whereas postlexical processes are strategic or controlled. Table 1 includes the theoretical features that are believed to distinguish between automatic (prelexical) processes and controlled (postlexical) processes and the experimental manipulations that have been used to operationalize this dichotomy. If prelexical processes are indeed automatic, then they should be (1) very fast (or, at least, faster than the controlled processes that occur after word access) and (2) unconscious (which is more likely if the subject's attention is not drawn to the dimensions in question, e.g., by choice of primary task, by use of a secondary "distractor" task, or by use of materials in which the proportion of relevant items is relatively low). On the basis of the same automatic/controlled dichotomy, it has also been argued that automatic forms of spreading activation are purely facilitative, whereas strategic or controlled processes may involve a combination of facilitation and inhibition; hence, if any inhibi- tion is observed, it is attributed to the operation of a strategic process.

Although we cannot pretend to have covered all these options in the present study (e.g., we will not adopt standard variations in SOA, speeded or delayed response, or perceptual degradation), we have selected tasks and materials that will permit us to interpret our results within the standard framework. Specifically, we are using online tasks in which subjects are working under a time pressure, with a short SOA between prime and target, and with systematic variations in the task, that ought to provide insights into behavior with and without conscious attention to the gender dimension. For present purposes, we want to know whether grammatical priming exists, and whether it meets any of the criteria in Table 1 for automatic priming effects.

We will show that gender priming in Italian does meet these criteria. This does not mean, however, that we are wedded to the standard framework. As we will point out in more detail in the conclusion, numerous problems have accrued for this two-stage model in the last few years (e.g., Smith, Besner, \& Miyoshi, 1994). An alternative framework has begun to emerge that is quite compatible with our results, based on Elman's recurrent network model (Elman, 1993). This alternative and its relevance for gender priming will be discussed in the conclusion.

\section{METHOD}

\section{Subjects}

Three independent groups of Italian-speaking university students participated in these experiments: 40 subjects in the word repetition task, 32 in the gender-monitoring task, and 20 in the grammaticality judgment task.

\section{Materials}

The stimuli for word repetition and gender monitoring were 120 adjective-noun phrases (adjective primes and noun targets, in the order adjective-noun ${ }^{1}$ ), constructed from a set of 120 nouns and 50 adjectives drawn from norms for spoken word frequency in Italian (De Mauro, Mancini, Vedovelli, \& Voghera, 1993). ${ }^{2}$ Foreign loan words, acronyms, slang terms, and proper names werc 
excluded, together with highly abstract, technical, or contextspecific terms. In a previous study of gender and lexical access in Italian (Bates et al., 1995), items with a word-initial fricative resulted in significantly slower reaction times. For the present study, selection of noun targets was therefore restricted to words that do not begin with a vowel or a fricative consonant. The Bates et al. study found no significant effects of semantic gender for words presented out of context (where semantic gender is defined as reference to animate beings with inherent sexual identity). However, to avoid any potential interactions between semantic and grammatical gender that might occur in a phrasal context, the 120 nouns used here all had inanimate referents (i.e., referents without inherent semantic gender).

The nouns included 60 phonologically transparent nouns ( 30 masculines ending with $o$ and 30 feminines endings with $a$ ) and 60 phonologically opaque nouns ( 30 masculines and 30 feminines, both ending with $e$ ). As noted earlier, all these nouns are unambiguous for gender, a fixed attribute known by all native speakers. The contrast between transparent and opaque nouns is not an ambiguity manipulation; rather, it permits us to assess the contribution of overt phonological cues to recognition and processing of inherent grammatical gender.

The adjectives included 40 phonologically transparent adjectives ending in $a$ or $o$ (to be used for concordant and discordant conditions, with feminine vs. masculine nouns, as outlined below) and 10 phonologically opaque adjectives ending in $e$ (to be used for the neutral control condition, outlined below). In contrast with nouns, adjectives ending in $e$ are ambiguous for gender. In Italian, gender is assigned to adjectives by the noun that they modify. For adjectives that belong to the dominant and phonologically transparent $-o /-a$ class, the final vowel will be $o$ if it modifies a masculine noun, and the final vowel will be $a$ if it modifies a feminine noun. For adjectives that belong to the ambiguous $-e$ class, the adjective takes the same form whether it modifies a masculine or a feminine noun. Hence, adjectives that end in $e$ offer no information at all about the subsequent noun. This means that these adjectives serve as a neutral baseline against which we can assess the facilitative or inhibitory effects on a phonologically transparent and unambiguously marked gender cue. Because such combinations are common in the Italian language, this means that our neutral baseline has substantial ecological validity.

All adjectives and nouns were singular forms, beginning with a consonant; half were two syllables long, and half were three syllables long. Note that there are no monosyllabic content words in Italian, except for foreign loan words, which means that our stimuli are longer than those that are ordinarily employed in Englishlanguage studies of lexical access (we will return to this point later). On the basis of the De Mauro et al. norms, nouns and adjectives have an absolute frequency of use ranging from 2 to 262 , with a mean of 40.46 and a standard deviation of 54.12. Care was taken to ensure that the four noun conditions (transparent masculine, transparent feminine, opaque masculine, and opaque feminine) did not differ significantly along any of the other dimensions that are known to influence auditory word recognition. Half of the nouns in each class were two syllables long, and half were three syllables long. We ran $2 \times 2$ gender and transparency analyses of variance (ANOVAs) over items on whole-word frequency and frequency of the inflected word form (based on the De Mauro et al. norms). There were no significant main effects of gender or transparency and no significant interactions (all $F_{\mathrm{S}}<1.00$, n.s.).

All adjectives were recorded by a male Italian native speaker, in a phrasal intonation (with a rise on the adjective and falling intonation on the noun), with a single carrier noun (cosa, or thing). All nouns were recorded separately by a female Italian native speaker, in the falling intonation that is appropriate for adjectivenoun pairs. The stimuli were digitized on the Macintosh SoundEdit 16 system. Adjective primes and noun targets were spliced from their original carrier phrase and stored in separate registers in the
PsyScope Experimental Shell (Cohen, MacWhinney, Flatt, \& Provost, 1993).

We also took pains to minimize differences between materials that might be due to word duration in milliseconds (measured by hand using the Macintosh SoundEdit 16 system; see below) or to length in milliseconds up to the point at which the word becomes uniquely identifiable (i.e., the uniqueness point). Identification of the uniqueness point was based on a comparison of each target noun with all possible word alternatives found in Palazzi (1973), and word stimuli were hand-measured up to this point on the SoundEdit 16 display system. Note that our procedures for determining the uniqueness point are necessarily different from those that are typically used for English, reflecting differences between English and Italian in inflectional and derivational morphology and in lexical stress. ${ }^{3}$ Mean word length was $891 \mathrm{msec}(S D=$ 128), which breaks down across materials as follows: feminine transparent, $857(S D=130)$; feminine opaque, $909(S D=127)$; masculine transparent, $879(S D=123)$; and masculine opaque, $919(S D=128)$. Mean length up to the uniqueness point was $722 \mathrm{msec}(S D=151)$, which breaks down across materials as follows: feminine transparent, $705(S D=182)$; feminine opaque, $728(S D=130)$; masculine transparent, $732(S D=156)$; and masculine opaque, $723(S D=135)$. Gender $\times$ transparency ANOVAs showed that there were no significant differences across conditions in total word duration or length up to the uniqueness point. All $F$ ratios were $<1.00$ (n.s.), except for a nonsignificant trend toward a main effect of phonological transparency on total word duration $[F(1,119)=3.89, p<.06]$. Examination of cell means showed that this trend comes from greater total durations for phonologically opaque nouns $(M=914 \mathrm{msec}, S D=126 \mathrm{msec}$, for nouns that end in $e ; M=868 \mathrm{msec}, S D=126 \mathrm{msec}$ for nouns that end in $a$ or $o$ ). Because the phonologically opaque class is relatively small in Italian (and we were limited to the corpus in De Mauro et al.), it was not possible to bring these stimuli into closer balance without creating differences in word frequency. However, we should take these small differences in total duration into account in interpreting main effects or interactions involving gender or transparency.

The above materials were used to prepare a set of 120 adjectivenoun pairs according to a 3 (concordant, discordant, neutral) $\times 2$ (masculine, feminine noun) $\times 2$ (transparent, opaque noun) design. Within these constraints, the PsyScope shell was used to create unique random assignments of noun targets to adjective primes and a unique ordering of noun-adjective pairs for each individual subject (see below). This means that our results cannot be due to fortuitous combinations of adjectives and nouns within a given condition (e.g., to the fact that some combinations are more semantically plausible than others), increasing our confidence that any effects we find are due to grammatical gender and not to hidden semantic effects. Noun targets were never repeated (i.e., PsyScope assigned nouns to adjective conditions within the $3 \times 2 \times 2$ design until all noun candidates were exhausted), but adjectives were repeated across trials (depending on results of a random assignment). Pilot studies within our laboratory suggest that repeated and nonrepeated primes result in priming effects that are similar in direction and magnitude, although this is an issue that merits further study.

This experimental design permits a comparison of facilitation (reaction time on concordant adjective-noun pairs compared with the neutral condition) and inhibition (reaction time on discordant adjective-noun pairs compared with the neutral condition). Examples of the resulting adjective-noun pairs used in the word repetition and gender-monitoring tasks are summarized in Table 2.

In contrast with the word repetition and gender-monitoring tasks, the grammaticality judgment task used only 80 adjectivenoun pairs: 40 concordant and 40 discordant. This is due to the fact that phonologically opaque adjectives (ending in $e$ ) are ambiguous for gender in Italian, so that any adjective-noun pair beginning with such an adjective is always grammatical. A pilot study of grammaticality judgment using all 120 adjective-noun 
Table 2

Sample Adjective-Noun Combinations

\begin{tabular}{|c|c|c|c|c|}
\hline \multicolumn{4}{|c|}{ Adiective and Transparent Noun } & \\
\hline \multicolumn{5}{|c|}{ Concordant Condition } \\
\hline $\begin{array}{l}\text { fem } \\
\text { masc }\end{array}$ & $\begin{array}{l}\text { Brutta-CASA } \\
\text { Brutto-PIATTO }\end{array}$ & $\begin{array}{l}\text { uggly }_{\text {fem }}-\text { HOUSE } \\
{\left[\text { ugly }_{\text {masc }}-\text { PLATE }\right.} \\
\text { masc }\end{array}$ & $\begin{array}{l}\text { Brutta-PACE } \\
\text { Brutto-CUORE }\end{array}$ & $\begin{array}{l}\left.\text { ugly }_{\text {fem }}-\text { PEACE }_{\text {fem }}\right] \\
\left.\text { ugly }_{\text {masc }}-\text { HEART }_{\text {masc }}\right]\end{array}$ \\
\hline \multicolumn{5}{|c|}{ Neutral Condition } \\
\hline $\begin{array}{l}\text { fem } \\
\text { masc }\end{array}$ & $\begin{array}{l}\text { Grande-CASA } \\
\text { Grande-PIATTO }\end{array}$ & $\begin{array}{l}{\left[\operatorname{large}_{\mathrm{amb}}-\text { HOUSE }_{\mathrm{fem}}\right]} \\
{\left[\operatorname{large}_{\mathrm{amb}}-\mathrm{PLATE} \mathrm{masc}_{\mathrm{mas}}\right]}\end{array}$ & $\begin{array}{l}\text { Grande-PACE } \\
\text { Grande-CUORE }\end{array}$ & $\begin{array}{l}{\left[\operatorname{large}_{\mathrm{amb}}-\mathrm{PEACE}_{\mathrm{fem}}\right]} \\
{\left[\operatorname{large}_{\mathrm{amb}}-\mathrm{HEART}_{\text {masc }}\right]}\end{array}$ \\
\hline \multicolumn{5}{|c|}{ Discordant Condition } \\
\hline $\begin{array}{l}\text { fem } \\
\text { masc }\end{array}$ & $\begin{array}{l}\text { Brutto-CASA } \\
\text { Brutta-PIATTO }\end{array}$ & $\left.\begin{array}{l}{\left[\text { ugly }_{\text {masc }}-\text { HOUSE }_{\text {fem }}\right]} \\
{\left[\text { ugly }_{\mathrm{fem}}-\text { PLATE }\right.} \\
\text { masc }\end{array}\right]$ & $\begin{array}{l}\text { Brutto-PACE } \\
\text { Brutta-CUORE }\end{array}$ & $\begin{array}{l}{\left[\text { ugly }_{\text {masc }}-\text { PEACE }\right.} \\
\left.\text { [ugly }_{\text {fem }}-\text { HEART }_{\text {masc }}\right]\end{array}$ \\
\hline
\end{tabular}

items clearly showed that Italian native speakers are fully aware of this fact, with some subjects pushing the "grammatical" button immediately after the adjective, before the noun was presented. Hence, the neutral adjective-noun pairs cannot serve as a baseline for the grammaticality judgment task. Note that the unique random assignment of nouns to adjective priming conditions for every individual subject precludes ANOVAs over items, but it also eliminates the need for such analyses, since individual items are not fixed across conditions (Clark, 1973).

Within each word pair, the onset of the noun target followed immediately after the offset of the adjective prime (i.e., an SOA set at zero). ${ }^{4}$ The noun target was followed by a 2,000 -msec window in which the subject could respond, followed by a fixed 500msec intertrial interval (ITI).

\section{Procedure}

The subjects were tested individually in a quiet room.

Word repetition task. The subjects in this experiment were told that they would hear pairs of words; within each pair, they were asked to repeat the second word (spoken by a female voice) as quickly as possible without making a mistake and to speak clearly into the microphone.

Reaction times (RTs) for word repetition were collected by a voice key contained within the Carnegie Mellon "button box," an ancillary of the Macintosh workstation that contains an independent timing crystal with $1 \mathrm{msec}$ accuracy. Reaction times were measured from the onset of the target word to the onset of the subject's repetition of that word and fed directly into a PsyScope file. The subjects had to respond within a 2,000 -msec response window (starting at the end of the target word); if they failed to respond or responded after that interval, a "nonresponse" was automatically registered for that trial. The 500 -msec ITI began after the 2,000-msec response window; this interval was fixed and did not vary as a function of the speaker's repetition time.

Gender monitoring. In this task, subjects were asked to place the index finger of their preferred hand on a spot between two plastic buttons. For each item, they were asked to indicate the gender of the target noun by pressing one button for feminine and the other for masculine (indicated by a symbol above each button). To control for possible differences in side preference, half of the subjects (randomly assigned) were tested with feminine on the left and masculine on the right, and the other half of the subjects were tested with masculine on the left and feminine on the right. They were asked to return the index finger to the central position after each response. RTs were calculated in milliseconds from the onset of the target to the subject's keypress (adjusted RTs from the word uniqueness point are described under data analysis, below). In all respects, timing parameters for the gender-monitoring task were equivalent to those described above for word repetition.
Grammaticality judgment. In this task, all procedures and timing parameters were the same as in the gender-monitoring task, but, in this case, the subject was asked to press one of two buttons indicating whether the adjective-noun pair was grammatical or ungrammatical (indicated above each button by a symbol). Button position for grammatical versus ungrammatical was counterbalanced over subjects.

For the gender-monitoring and grammaticality judgment tasks, number of correct responses was also recorded by the button box and fed directly into the PsyScope file. For the word repetition task, errors (i.e., production of the wrong word) were noted manually by the experimenter.

\section{RESULTS}

\section{Word Repetition Task}

Accuracy. Errors on word repetition were rare in this experiment, averaging one to three errors per subject (i.e., less than $1 \%$ ) and were not subjected to further analyses.

Reaction time. The mean RT for word repetition was $955 \mathrm{msec}(S D=147 \mathrm{msec})$. This may seem relatively long in comparison with the RTs found in many studies of word recognition in English, but it is important to remember that these two- and three-syllable Italian words are considerably longer than the words used in most Englishlanguage studies. When RTs are measured from the uniqueness point, the mean for word repetition was $233 \mathrm{msec}(S D=148 \mathrm{msec})$, which suggests that most words were recognized and reproduced less than $250 \mathrm{msec}$ after the information required to identify the word out of context is available.

A 3 (concordant, neutral, discordant) $\times 2$ (feminine, masculine) $\times 2$ (transparent, opaque ending) ANOVA was performed on the RTs measured from the onset of each word. The results showed two significant main effects: for adjective-noun concordance $[F(2,78)=19.76$, $p<.0001]$ and for noun gender $[F(1,39)=60.76, p<$ $.0001]$. No interaction was significant in this analysis.

The main effect of concordance was in the predicted direction: concordant $(934 \mathrm{msec}, S D=147 \mathrm{msec})<$ neutral $(953 \mathrm{msec}, S D=145 \mathrm{msec})<\operatorname{discordant}(978 \mathrm{msec}$, $S D=144 \mathrm{msec})$. The difference between concordant and neutral was significant by a planned one-tailed $t$ test $[t(39)=2.57, p<.01]$, as was the difference between dis- 
cordant and neutral $[t(39)=3.99, p<.0002]$, suggesting robust effects of facilitation and inhibition, respectively. The main effect of noun gender reflects faster RTs on feminine nouns (938 $\mathrm{msec}, S D=147 \mathrm{msec}$ ) than on masculine nouns ( $972 \mathrm{msec}, S D=144 \mathrm{msec}$ ). The main effect of transparency was not reliable.

Comments. These findings show a robust genderpriming effect in the word repetition task, an effect that involves both facilitation and inhibition, relative to an ecologically valid neutral baseline. The fact that gender priming occurs within such a short time window indicates that gender is processed very early in the word recognition process.

In addition to these predicted effects of adjective gender on noun repetition, we did find a significant main effect of noun gender, with faster response to feminine words. This finding is in the opposite direction from what we might predict on the basis of type frequency (i.e., there are more masculine than feminine word types in the Italian language as a whole). Despite all of our controls on word selection in the present experiment, it is possible that performance is affected by hidden correlates of gender and phonological transparency in the Italian language, similar to the many phonological and semantic correlates that Zubin and Köpcke (1981) have uncovered for gender in German. These significant differences in RT may also reflect measurable (albeit nonsignificant) differences in total duration as a function of gender and transparency (see Method section). The crucial point for the present purposes is that these differences among materials did not interact with priming conditions.

\section{Gender-Monitoring Task}

Accuracy. Accuracy scores in this task were high, averaging $96 \%$ across all conditions. Because it would be possible to obtain interactions that are due entirely to ceiling effects, these scores were not subjected to further analyses.

Reaction time. Measured from word onset, the mean RT for gender monitoring was $1,147 \mathrm{msec}(S D=$ $172 \mathrm{msec}$ ), which corresponds to a mean of $425 \mathrm{msec}$ from the uniqueness point. These RTs were approximately $200 \mathrm{msec}$ longer than the RTs for word repetition, in line with findings by Bates et al. (1995) for single words presented out of context in both tasks.

A $3 \times 2 \times 2$ ANOVA, similar to that performed on data of the word repetition task, was performed on RTs measured from the onset of each word. All three main effects were significant for concordance $[F(2,62)=5.14$, $p<.009]$, noun gender $[F(1,31)=28.16, p<.0001]$, and transparency $[F(1,31)=66.14, p<.0001]$. None of the interactions reached significance.

The concordance effect was in the predicted direction: concordant $(1,135 \mathrm{msec}, S D=177 \mathrm{msec})<$ neutral $(1,145 \mathrm{msec}, S D=170 \mathrm{msec})<$ discordant $(1,161 \mathrm{msec}$, $S D=168 \mathrm{msec}$ ). The difference between neutral and discordant pairs was reliable by a planned one-tailed $t$ test $[t(31)=1.88, p<.04]$, but the difference between concordant versus neutral pairs was not, although there was a trend in that direction $[t(31)=1.49, p<.08]$. Hence, the inhibitory component for gender monitoring is reliable, but the facilitative component misses significance, in contrast with our findings for word repetition.

The main effect of gender in this task is similar in direction to the main effect for word repetition, with faster RTs on feminine words ( $M=1,124 \mathrm{msec}, S D=$ $168 \mathrm{msec})$ than on masculine words $(M=1,170 \mathrm{msec}$, $S D=165 \mathrm{msec}$ ). As noted above, this significant difference may reflect nonsignificant but measurable differences in word duration for feminine versus masculine words. The main effect of phonological transparency reflects faster RTs on transparent nouns ending in $a$ or $o$ $(1,116 \mathrm{msec}, S D=168 \mathrm{msec})$ compared with phonologically opaque nouns ending in $e(1,178 \mathrm{msec}, S D=$ $171 \mathrm{msec})$. This finding is in line with previous results by Bates et al. (1995) for gender monitoring of single words presented out of context. Recall, however, that there was also a nonsignificant trend toward longer word durations for phonologically opaque nouns, which may have contributed to this effect.

Comments. Results obtained with gender monitoring match our results for word repetition in two respects. The priming effect reached significance on both tasks, and, on both tasks, feminine words elicited faster RTs than did masculine words. In contrast with the word repetition task (which yielded significant facilitation and inhibition when RTs were measured from word onset), gender monitoring provided evidence for significant inhibition, but the facilitative component was not reliable. There was also a difference between tasks in the effect of phonological transparency: Words that end with the opaque vowel $e$ elicited slower RTs in gender monitoring; there was no corresponding effect of transparency on word repetition. Again, it is important to underscore that these differences across materials did not interact with priming conditions.

\section{Grammaticality Judgment Task}

Accuracy. Accuracy on the grammaticality judgment task was (again) very high, with an average of $97 \%$ correct. No further analyses were conducted on these data.

Reaction time. The mean RT for grammaticality judgment measured from word onset was $1,271 \mathrm{msec}$ $(S D=175 \mathrm{msec})$, corresponding to a mean of $548 \mathrm{msec}$ from the uniqueness point. Overall, this was the slowest response observed across our three tasks (i.e., compared with means of $955 \mathrm{msec}$ for word repetition and $1,147 \mathrm{msec}$ for gender monitoring).

The 2 (concordant, discordant) $\times 2$ (masculine, feminine) $\times 2$ (transparent, opaque) ANOVA was conducted on RTs measured from word onset. Two main effects were significant: concordance $[F(1,19)=14.92, p<$ $.001]$, and phonological transparency $[F(1,19)=18.08$, $p<.0001]$. The concordance effect reflects faster responses for concordant items (which must be classified as "grammatical") than for discordant items (which must be classified as "ungrammatical"). Specifically, the means were $1,127 \mathrm{msec}$ for concordants ( $S D=170 \mathrm{msec}$ ) versus 
$1,314 \mathrm{msec}$ for discordants $(S D=170 \mathrm{msec})$. The transparency effect reflects faster grammaticality judgments for transparent $-a /-o$ endings $(M=1,249 \mathrm{msec}, S D=$ $175 \mathrm{msec})$ compared with opaque $-e$ endings $(M=$ $1,292 \mathrm{msec}, S D=174 \mathrm{msec}$ ), similar to our findings for gender monitoring. The main effect of gender was not reliable.

In this task, there was also a significant interaction between gender and ending $[F(1,19)=6.21, p<.02]$. Inspection of cell means shows that the fastest RTs were observed on feminine nouns with a phonologically transparent ending $(M=1,243 \mathrm{msec}, S D=183 \mathrm{msec})$, whereas the slowest RTs were observed on feminine nouns with a phonologically opaque ending $(M=1,314 \mathrm{msec}$, $S D=186 \mathrm{msec}$ ); intermediate figures were observed for masculine nouns (transparent, $M=1,255 \mathrm{msec}, S D=$ $169 \mathrm{msec}$; opaque, $M=1,271 \mathrm{msec}, S D=160 \mathrm{msec}$ ). Because we had no predictions regarding main effects or interactions involving gender (i.e., masculine vs. feminine), we will not explore this interaction further, except to note that it apparently does not interact with or override priming effects.

Comments. The concordance results for grammaticality judgment provide further support for the importance of grammatical context, showing in this case that the judgment of items that agree in gender is faster than the recognition of gender disagreements. Noun gender and the transparency of gender marking also contribute to the timing of grammaticality judgment, although the basis for this interaction among materials is not clear.

Table 3 presents a summary of RT results across these three experiments. Strictly speaking, the concordance effect on grammaticality judgment is not a priming effect, since a different response is required for concordant versus discordant items. However, results are compatible with the idea that Italian native speakers find items with gender disagreement difficult to process. It is also interesting that grammaticality judgment was the slowest of our three tasks. In the absence of this information, one might propose that the inhibitory effects in word repetition and gender monitoring are due to a conscious, metalinguistic reaction to the adjective-noun mismatch.

Table 3

Summary of Adjective-Noun Priming Results Across Three Tasks

\begin{tabular}{|c|c|c|c|}
\hline & $\begin{array}{c}\text { Word } \\
\text { Repetition }\end{array}$ & $\begin{array}{c}\text { Gender } \\
\text { Monitoring }\end{array}$ & $\begin{array}{c}\text { Grammaticality } \\
\text { Judgment }\end{array}$ \\
\hline \multicolumn{4}{|c|}{ Mean Reaction Times } \\
\hline From word onset & 955 & 1,147 & 1,271 \\
\hline From uniqueness point & 233 & 425 & 548 \\
\hline Concordant & 934 & 1,135 & 1,127 \\
\hline Neutral & 953 & 1,145 & n.a. \\
\hline Discordant & 978 & 1,161 & 1,314 \\
\hline \multicolumn{4}{|c|}{ Difference Scores } \\
\hline Facilitation $(\mathrm{N}-\mathrm{C})$ & $19^{*}$ & $10^{\dagger}$ & n.a. \\
\hline Inhibition $(D-N)$ & $25^{*}$ & $16^{*}$ & n.a. \\
\hline Total $(D-C)$ & $44^{*}$ & $26^{*}$ & $187^{*}$ \\
\hline
\end{tabular}

However, when subjects are instructed to report whether a mismatch has taken place (through grammaticality judgment), they are substantially slower than are subjects who are asked to repeat the word or classify it according to gender. The potential importance of this finding is discussed below.

\section{DISCUSSION}

The main question addressed in the present study concerns the possible influence of grammatical gender in word recognition. The answer to this question is clear: Robust priming effects are observed in Italian when target nouns are preceded by a gender-marked adjective prime for tasks with very different properties. In particular, priming is observed whether or not the subject's attention is drawn to gender or gender marking.

A second question concerns the direction of effects in gender priming. Because the Italian language provides a valid baseline control (through the use of genderambiguous adjectives), we were able to show that gender priming involves a reliable inhibitory component across tasks (i.e., incongruent nouns are slower than neutral controls). Evidence for facilitation (congruent nouns faster than neutral controls) was obtained only in the word repetition task, although there is a tendency in the facilitative direction for gender monitoring as well $(p<.08)$.

A further issue revolves around the nature and locus of gender priming. As we noted in the introduction, many investigators have concluded that grammatical priming (if it exists at all) reflects operations that are controlled, strategic, inhibitory, and/or postlexical (Balota, 1992; Friederici \& Kilborn, 1989; Tanenhaus \& Lucas, 1987; Tyler \& Wessels, 1983). Four aspects of the findings presented here support an alternative view-that is, that at least part of the variance in gender priming is contributed by automatic processes that occur at some point prior to word recognition and are similar to those that Italian native speakers use in everyday language processing.

1. In all three tasks, the difference between congruent and incongruent conditions was robust even though the predictive validity of the prime was $50 \%$ (i.e., a chance relationship between gender of the prime and gender of the target). If the subjects were responding with controlled and task-specific strategies, then their best course in the word repetition and gender-monitoring tasks would be to ignore the gender-marked adjective altogether (since it offers completely unreliable information within the context of these experiments). It appears that the subjects could not or did not develop such an experimentspecific strategy. We suggest that this is due to the very high predictive validity of gender in the Italian language (i.e., in the real world), resulting in a rapid and automatic response to gender information that is difficult for native speakers to suppress---even when it would be convenient to do so.

2. The presence of gender priming in the word repetition task suggests that explicit attention to gender is not required for priming to occur. Of course, we are in no position to conclude that gender priming is unconscious, 
even in the word repetition task. As Grosjean et al. (1994) have noted, gender errors are highly salient for native speakers of a gender-marked language, so salient that a single mismatch can bring about what Grosjean et al. refer to as a "processing catastrophe." It is unlikely that we could create a laboratory situation in which Italian listeners are unaware of gender agreement errors. We can conclude, however, that gender priming occurs whether or not the task requires metalinguistic awareness of the gender dimension.

3. RTs in the word repetition task were very fast (i.e., an average of $233 \mathrm{msec}$ after the uniqueness point). This is all the more impressive in view of the fact that the target followed immediately after the offset of the prime, approximating the timing relations between adjectives and nouns in natural discourse. This finding is compatible with the idea that gender priming involves (at least in part) a rapid, automatic form of activation that contributes to word recognition in Italian.

4. Although the inhibitory component of gender priming is clearly more robust than the facilitative component, the presence of facilitation as well as inhibition on the word repetition task is compatible with a mix of automatic and controlled processes.

With regard to this last point, inhibitory effects are classically considered to be strong evidence for controlled processing (Posner \& Snyder, 1975). However, more recent studies have shown that inhibition may appear even in tasks where several indicators point to an automatic processing (i.e., fast, unconscious, and rapidly decaying inhibitory effects in color priming-Di Pace, Marangolo, Pizzamiglio, \& Burr, 1994; Marangolo, Di Pace, \& Pizzamiglio, 1993; inhibitory effects in picture-word Stroop tasks that only occur with very short SOAs-Glaser, 1992; see Dagenbach \& Carr, 1994, for detailed discussions of the role of inhibition in information processing). In view of all these findings, we suggest that the presence of inhibitory gender priming in the present study could reflect automatic processing, controlled processing, or both. In other words, the presence of inhibition may not be a useful guide to the locus of priming effects, even though such effects have been used to argue for controlled processing in previous studies (e.g., Nebes, Boller, \& Holland, 1986; Nebes, Martin, \& Horn, 1984; for detailed discussions of this point, see Dagenbach \& Carr, 1994).

In addition to the predicted priming effects, there were also a number of effects involving noun gender (masculine vs. feminine) and noun ending (opaque vs. transparent). In gender monitoring and in grammaticality judgment, nouns with a phonologically transparent ending $(-o$ or $-a)$ were processed more quickly than were nouns with a phonologically opaque ending. This replicates our previous findings for gender monitoring of single words out of context (Bates et al., 1995), and it suggests that Italian native speakers find it easier to make an explicit decision about gender when there is a transparent and unambiguous phonological cue to gender at the end of the word. Following the standard model, this pre- dicted effect of phonological transparency may be postlexical in nature, reflecting a process of "checking" that some subjects engage in, on some items, when they are required to make an explicit decision about gender identity and gender agreement. The fact that transparency effects were not observed in the word repetition task (similar to out-of-context findings by Bates et al., 1995) provides further support for this view.

On gender monitoring and word repetition, the subjects responded more quickly overall to feminine nouns. On grammaticality judgment, there was no main effect of gender. These judgments were particularly fast for transparent feminine words (in line with findings for the other two tasks), but especially slow for opaque feminine words (an interaction that was not observed in the other two tasks, although it was observed by Bates et al., 1995, for gender monitoring of single words out of context). These gender effects cannot be explained by word frequency or length (which were counterbalanced over genders), although (as noted earlier) they may reflect nonsignificant but measurable differences in total word duration. Because we made no specific predictions regarding the effects of noun gender, we think it would be unwise to speculate in detail about the source of all these complex interactions, except to note that they do not override our predicted effects of priming.

To summarize, we have shown that gender priming is a reliable phenomenon that meets many of the criteria that have been proposed by others for automatic, modular, prelexical (or prerecognition) effects. Our data do not permit us to specify the locus of gender priming within this broad prerecognition stage (e.g., it may occur before the target is presented or after lexical candidates are activated). However, our findings do have implications for modular theories, if one adopts the criteria that are typically used to define automatic processes (Table 1), because they suggest that lexical processes may be "penetrated" by higher level phrasal information. Can the modular view be saved?

One possibility may be that gender priming occurs entirely within the lexicon, by analogy to the semantic activation that spreads from word to word to yield classic semantic priming effects (e.g., why DOCTOR-NURSE is faster than BREAD-NURSE). On this argument, gender priming would have nothing to do with higher level grammar; rather, words of the same gender tend to activate each other, independent of structure.

Although this is a logical possibility, it is unlikely that it would work for a language like Italian. There are only two genders, and there are often many nouns, adjectives, and other elements of the same gender within a single sentence or phrase. If gender priming were structureindependent (i.e., it had nothing to do with agreement, as specified by syntactic relations), then such priming effects could do far more harm than good. Consider the following Italian sentence:

Perche la trova così bella, Giovanni ha invitato Maria alla festa. 
[Because her feminine-object-clitic finds so beautiful $_{\text {feminine }}$, Giovanni ${ }_{\text {masculine }}$ invited Maria feminine $_{\text {to the party }}$ feminine.]

Note that the feminine adjective bella (beautiful) modifies Maria, but it immediately precedes the noun Giovanni (John). If gender priming spreads forward in a structure-independent manner, it would erroneously block or inhibit perception of the noun that serves as the subject of the next clause. Furthermore, because adjectives can precede or follow their nouns in Italian (depending on various syntactic, semantic, and pragmatic conditions), the risk of erroneous structure-independent priming could run in two directions. Although we cannot rule out the possibility that our effects are due to structureindependent intralexical effects, the danger that such effects would portend for lexical and grammatical processing in Italian suggests that gender priming must be constrained by structural relations.

Could we, then, move all structurally constrained gender priming into the lexicon? That is a possibility as well; however, given the pervasiveness of gender agreement at many different levels of the grammar in Italian, such a move is tantamount to placing all of grammar within the lexicon. In fact, a number of proposals of that type have been put forward in the last few years within linguistic theory, eliminating the border between grammar and the lexicon in favor of a single, heterogeneous "construction-based" system (e.g., Goldberg, 1995). Hence, this may be a reasonable move from a linguistic point of view. However, if we eliminate the distinction between grammar and the lexicon, then the classic psycholinguistic distinction between prelexical and postlexical processes loses much of its value.

Our findings could be accommodated by an interactive alternative to the standard theory, one that also eliminates the need for a neutral baseline against which facilitation and inhibition are carefully measured. In interactive-activation models of lexical access, many different sources of information can be brought to bear in the word recognition process (e.g., Bates, Elman, \& Li, 1994; Elman, 1993; Elman \& McClelland, 1988; MacDonald, Pearlmutter, \& Seidenberg, 1994; MacWhinney, 1989; Rumelhart \& McClelland, 1986; Simpson \& Kang, 1994). Interlexical relations, syntactic information, and discourse context can all be used to activate word candidates, sometimes in advance of the actual physical signal (by lowering the thresholds of some lexical candidates and/or raising the thresholds of others). This activation process is inherently nonlinear, so that the rise and fall of lexical candidates can mimic the discontinuities assumed by traditional modular models. However, the underlying process of candidate activation is continuous and is distributed in time as well as (mental) space.

The time-space interactions assumed by such models are important for our purposes here, because they suggest a way that candidates could be facilitated or suppressed without assuming anything resembling a neutral baseline. In the present study, we have taken advantage of a neutral baseline that is a valid and frequent property of Italian (i.e., gender-ambiguous adjectives, contrasting with gender-marked adjectives that either match or mismatch the subsequent noun). By using such a baseline, we have been able to demonstrate that gender priming in Italian reflects both facilitation and inhibition (assuming that the standard model is correct). Nevertheless, we are uncomfortable with the standard view of facilitation and inhibition for two reasons. First, the terms facilitation and inhibition resemble terms with well-specified meanings in the brain sciences, and, as such, they imply more than we really know about the processes responsible for lexical activation. Second, an empirical test of the distinction between facilitation and inhibition always requires establishment of a neutral baseline. But what really constitutes a fair estimate of "neutral language" once we move beyond the level of word pairs? We have been fortunate in finding a reasonable and valid example of a neutral baseline for grammatical priming in Italian, but such baselines are rarely available once one moves beyond the level of word pairs to more complex semantic and grammatical contexts (see Neely, 1991, for a discussion of this point).

A recent proposal by Elman (1993) offers a way to explain positive and negative context effects without assuming an artificial and unrealistic neutral starting point. Elman has implemented an interactive-activation model of lexical access in a mechanism called a simple recurrent neural network. This is an artificial neural network that lives in time. On each time step, the system uses a combination of the current input and previous context to make a prediction about the linguistic element that will occur next (in this case, the next word). On the basis of the degree of mismatch between the predicted element and the element that actually occurs, the system modifies its internal state and uses those modifications to make its next prediction. Elman has shown that a system of this sort is able to induce a phrase structure grammar from unlabeled strings of words that were generated by such a grammar. Under certain developmental conditions, such systems can induce a grammar with multiple embeddings and long-distance dependencies (including agreement phenomena). The crucial point for our purposes here revolves around the nature of the underlying representations that make this performance possible. Words are represented as vectors in a high-dimensional space, and (after learning has occurred) words with similar grammatical privileges are grouped closely together within this $n$-dimensional space. As it acquires the grammar of this artificial language, the system acquires (1) an appropriate spatial organization (with elements sent to live in the proper space) and (2) a set of weights that permit movement from one position to another in this space over time. Hence, grammatical "knowledge" can be viewed as a set of probabilistic trajectories. Figure 1 (from Bates et al., 1994) illustrates a three-dimensional reduction of this hyperspace (based on the first principal com- 


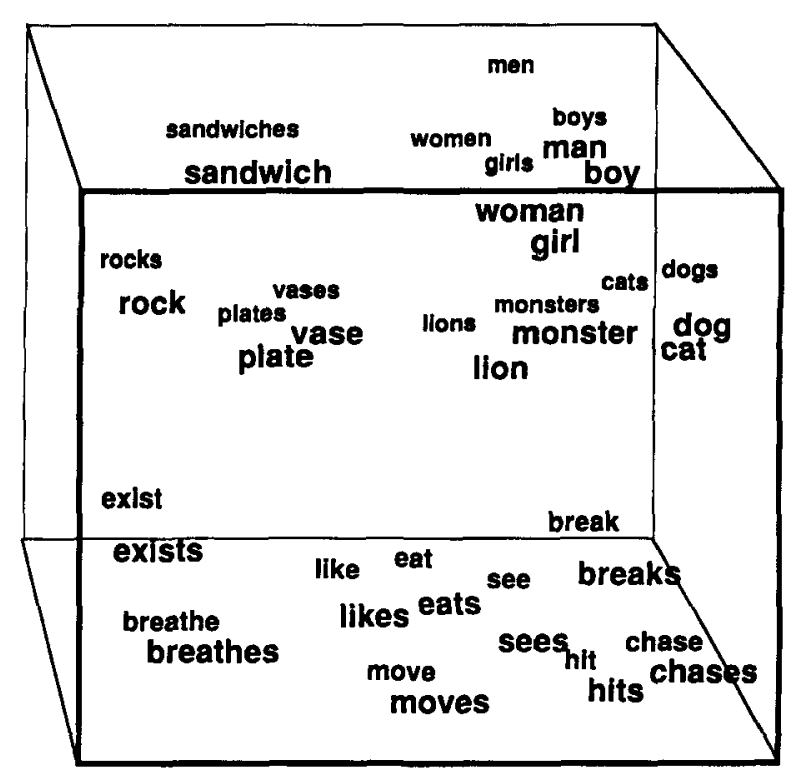

Figure 1. Schematic representation of hidden-unit activation patterns as vectors in an $\boldsymbol{n}$-dimensional state space. Lexical items are points in space; different regions correspond to grammatical categories or semantic features. Modified version of figure in Elman (1993) and adapted in Bates et al. (1994), provided by J. EIman.

ponents of the Elman simulation). Given a sentence beginning (for example) with a plural word like Dogs, a system that has acquired this simple phrase structure grammar will make a prediction that constitutes (formally) a move in the direction of the verb sector of space, with a strong bias toward plural verbs associated with animate first nouns (e.g., eat). The match or mismatch between predicted words and the word that actually occurs next is a dynamic and continuous variable (i.e., success is a matter of degree).

Applying the same logic to gender priming, we may view the effect of a gender-marked adjective on a subsequent noun as a trajectory in a similar multidimensional space. If the adjective causes a move closer to the noun that actually occurs, we have the equivalent of facilitation; if the adjective causes a move farther from the noun that actually occurs (i.e., farther than the system was before the adjective occurred), then we would have the equivalent of inhibition. However, because this is a continuous multidimensional space where movements are always relative to some (arbitrary) position, there is no need to postulate a single, neutral starting point. We may measure the relative contribution of two primes (e.g., a matching vs. a mismatching adjective) without assuming a neutral baseline.

Our results cannot be used to decide between the standard model and this interactive-activation account. Indeed, they are compatible with both. What we have shown is that gender agreement has an effect on word recognition-an effect that is fast, robust, and consonant with known facts about the Italian language. Future research will have to determine whether these effects are prelex- ical, lexical, postlexical, or part of a continuous processing stream.

\section{REFERENCES}

BALOTA, D. (1992). Visual word recognition: The journey from feature to meaning. In M. Gernsbacher (Ed.), Handbook of psycholinguistics (pp. 303-357). New York: Academic Press

Bates, E., Devescovi, A., Pizzamiglio, L., D'Amico, S., \& HernanDEZ, A. (1995). Gender and lexical access in Italian. Perception \& Psychophysics, 57, 847-862.

Bates, E., Elman, J., \& Li, P. (1994). Language in, on, and about time. In M. Haith, J. Benson, R. Roberts, \& B. Pennington (Eds.), The development of future-oriented processes ( $\mathrm{pp}$. 293-322). Chicago: University of Chicago Press.

Brooks, J., Braine, M. D. S., Catalano, L., Brody, R. E., \& SudHALTER, V. (1993). Acquisition of gender-like noun subclasses in an artificial language: The contribution of phonological markers to learning. Journal of Memory \& Language, 32, 76-95.

Brown, P., SENFT, G., \& WheELDON, L. (EDS.) (1993). Max Planck Institute for Psycholinguistics: Annual Report 1992. Nijmegen, The Netherlands: Max Planck Psycholinguistics Institute.

Burani, C. (1992). Patterns of inflectional errors with reference to the Italian adjectival system. Rivista di Linguistica, 4, 255-272.

CAssidy, K., \& KELLY, M. (1991). Phonological information for grammatical category assignment. Journal of Memory \& Language, $\mathbf{3 0}$, 348-369.

Chiarello, C. (1991). Interpretation of word meanings by the cerebral hemispheres: one word is not enough. In P. Schwanenflugel (Ed.), The psychology of word meanings (pp. 251-278). Hillsdale, NJ: Erlbaum.

CLARK, H. (1973). The language-as-fixed-effect fallacy: A critique of language statistics in psychological research. Journal of Verbal Learning \& Verbal Behavior, 12, 335-359.

Cohen J., MacWhinney, B., Flatt, M., \& Provost, J. (1993). PsyScope: An interactive graphic system for designing and controlling experiments in the psychology laboratory using Macintosh computers. Behavior Research Methods, Instruments, \& Computers, 25, 257-271.

COLÉ, P., \& SEGUI, J. (1994). Grammatical incongruency and vocabulary types. Memory \& Cognition, 22, 387-394.

DAGENBACH, D., \& CARR, T. H. (EDS.) (1994). Inhibitory processes in attention. memory, and language. San Diego: Academic Press.

De Mauro, T., Mancini, F., Vedovelli, M., \& Voghera, M. (1993). Lessico di frequenza dell'italiano parlato [Frequency dictionary of spoken Italian]. Rome: Fondazione IBM Italia.

Deutsch, W., \& WiJnen, F. (1985). The article's noun and the noun's article: Explorations into the representation and access of linguistic gender in Dutch. Linguistics, 23, 793-810.

Devescovi, A., D'Amico, S., Smith, S., Mimica, I., \& Bates, E. (1994). The development of sentence comprehension in Italian and Serbo-Croatian: Local versus distributed cues. Manuscript submitted for publication.

Di Pace, E., Marangolo, P., Pizzamiglio, L., \& Burr, D. (1994). Colour-priming does not depend on spatial coincidence or conscious encoding strategies. Manuscript submitted for publication.

ElMaN, J. (1993). Learning and development in neural networks: The importance of starting small. Cognition, 48, 71-99.

Elman, J. L., \& MCClelland, J. L. (1988). Cognitive penetration of the mechanisms of perception: Compensation for coarticulation of lexically restored phonemes. Journal of Memory \& Language, 27, 143-165.

Frauenfelder, U., \& TYler, L. (EDS.) (1987), Spoken word recognition. Cambridge, MA: MIT Press/Bradford Books.

FrIEDERICI, A., \& KilboRn, K. (1989). Temporal constraints on language processing: Syntactic priming in Broca's aphasia. Journal of Cognitive Neuroscience, 1, 262-272.

FrIEDERICI, F., \& SCHRIEFERS, H. (1993). Semantic and morphosyntactic context effects on word recognition: The influence of peripheral and central processing variables. Unpublished manuscript, Cognitive Science Lab, Institut für Psychologie, Berlin. 
Gernsbacher, M. (ED.) (1994). Handbook of psycholinguistics. New York: Academic Press.

Glaser, W. (1992). Picture naming. Cognition, 42, 61-105.

GoldBerG, A. (1995). Constructions: A construction grammar approach to argument structure. Chicago: University of Chicago Press.

Goodman, G. O., McClelland, J. L., \& Gibis, R. W., JR. (1981). The role of syntactic context in word recognition. Memory \& Cognition, 9, 580-586.

Grosjean, F., Dommergues, J.-Y., Cornu, E., Gulllelmon, D., \& Besson, C. (1994). The gender-marking effect in spoken word recognition. Perception \& Psychophysics, 56, 590-598.

Hernandez, A. E., Bates, E., \& Avila, L. X. (in press). Processing across the language boundary: A cross-modal priming study of Spanish-English bilinguals. Journal of Experimental Psychology: Learning, Memory, \& Cognition.

HERRON, D. (1994). The effect of acoustic clarity and grammatical role on the processing of open and closed-class words. Unpublished master's thesis, University of California, San Diego.

Jarema, G., \& Friederici, A. (1994). Processing articles and pronouns in agrammatic aphasia: Evidence from French. Brain \& Language, 46, 683-694.

KaIL, M. (1989). Cue validity, cue cost, and processing types in sentence comprehension in French and Spanish. In B. MacWhinney \& E. Bates (Eds.), The crosslinguistic study of sentence processing (pp. 77-117). New York: Cambridge University Press.

KILBORN, K. (1987). Sentence processing in a second language: Seeking a performance definition of fluency. Unpublished doctoral dissertation, University of California, San Diego.

KILBORN, K., \& FrIEDERICI, A. (in press). Cognitive penetrability of syntactic priming in Broca's aphasia. Neuropsychology.

LeVELT, W. J. M. (ED.) (1992). Lexical access in speech production [Special issue]. Cognition, 42(1-3).

LiU, H., Bates, E., Powell, T., \& Wulfeck, B. (in press). Single-word shadowing and lexical access: A lifespan study. Applied Psycholinguistics.

Lukatela, G., Kostić, A., Feldman, L. B., \& Turvey, M. T. (1983). Grammatical priming of inflected nouns. Memory \& Cognition, 11 , 59-63.

MacDonald, M. C., Pearlmutter, N. J., \& Seidenberg, M. S. (1994). The lexical nature of syntactic ambiguity resolution. Psychological Review, 101, 676-703.

MACWhinNeY, B. (1978). The acquisition of morphophonology. Monographs of the Society for Research in Child Development, 43, (Whole No. 174).

MacWhinney, B. (1989). Competition and connectionism. In B. MacWhinney \& E. Bates (Eds.), The crosslinguistic study of sentence processing (pp. 442-457). New York: Cambridge University Press.

Marangolo, P., Di Pace, E., \& Pizzamiglio, L. (1993). Priming effect in a color discrimination task. Perceptual \& Motor Skills, 77, 259-269.

MARSLEN-Wilson, W., \& TYLER, L. (1980). The temporal structure of spoken language understanding. Cognition, 8, 1-71.

Nebes, R., Boller, F., \& Holland, A. (1986). Use of semantic context by patients with Alzheimer's disease. Psychology \& Aging, 1, 261-269.

Nebes, R., Martin, D., \& Horn, L. (1984). Sparing of semantic memory in Alzheimer's disease. Journal of Abnormal Psychology, 93, 321-330.

NeELY, J. H. (1991). Semantic priming effects in visual word recognition: A selective view of current findings and theories. In D. Besner \& G. W. Humphreys (Eds.), Basic processes in reading: Visual word recognition (pp. 264-336). Hillsdale, NJ: Erlbaum.

ORsol.INI, M. (1993, July). Children's semantic processing of gender cues. Paper presented at the Sixth International Congress for the Study of Child Language, Trieste, Italy.

PalazzI, F. (1973). Novissimo dizionario della lingua italiana [New dictionary of the Italian language]. Milan: Ceschino.

Pizzuto, E., \& Caselli, M. C. (1992). Acquisition of Italian morphology and its implications for models of language development. Journal of Child Language, 19, 491-557.
PoSNER, M., \& SNYDER, C. (1975). Attention and cognitive control. In R. Solso (Ed.), Information processing and cognition: The Loyola symposium (pp. 55-85). Hillsdale, NJ: Erlbaum.

RadeaU, M., \& Morais, J. (1990). The uniqueness point effect in the shadowing of spoken words. Speech Communication, 9, 155-164.

Radeau, M., Mousty, P., \& Bertelson, P. (1989). The effect of the uniqueness point in spoken-word recognition. Psychological Research, 51, 123-128.

Rumelhart, D., \& McClelland, J. (1986). Parallel distributed processing: Explorations in the microstructure of cognition. Cambridge, MA: MIT Press/Bradford Books.

SeidenberG, M. S., Waters, G. S., Sanders, M., \& Langer, P. (1984). Pre- and postlexical loci of contextual effects on word recognition. Memory \& Cognition, 12, 315-328.

SHIFFrin, R., \& SCHNEIDER, W. (1977). Controlled and automatic processing II: Perceptual learning, automatic attending and a general theory. Psychological Review, 84, 127-190.

Simpson, G. B., \& Kang, H. W. (1994). Inhibitory processes in the recognition of homograph meanings. In D. Dagenbach \& T. H. Carr (Eds.), Inhibitory processes in attention, memory, and language (pp. 359-381). San Diego: Academic Press.

SLOWIACZEK, L. M. (1994). Semantic priming in a single-word shadowing task. American Journal of Psychology, 107, 245-260.

Smith, M., Besner, D., \& Miyoshi, H. (1994). New limits to automaticity: Context modulates semantic priming. Journal of Experimental Psychology: Learning, Memory, \& Cognition, 20, 104-115.

SWINNEY, D. (1979). Lexical access during sentence comprehension: (Re)consideration of context effects. Journal of Verbal Learning \& Verbal Behavior, 18, 645-659.

TABOSSI, P., \& ZARDON, F. (1993). Processing ambiguous words in context. Journal of Memory \& Language, 32, 359-372.

Tanenhaus, M., \& Lucas, M. (1987). Context effects in lexical processing. In U. Frauenfelder \& L. Tyler (Eds.), Spoken word recognition (pp. 213-233). Cambridge, MA: MIT Press/Bradford Books.

TYLER, L. K., \& Wessels, J. (1983). Quantifying contextual contributions to word-recognition processes. Perception \& Psychophysics, 34, 409-420.

WEST, R., \& Stanovich, K. (1982). Source of inhibition in experiments on the effect of sentence context on word recognition. Journal of Experimental Psychology: Learning, Memory, \& Cognition, 8, 385-399.

WEST, R. F., \& STanovich, K. E. (1986). Robust effects of syntactic structure on visual word processing. Memory \& Cognition, 14, 104112.

Wright, B., \& Garrett, M. (1984). Lexical decision in sentences: Effects of syntactic structure. Memory \& Cognition, 12, 31-45.

ZuBin, D., \& KöPCKE, K. (1981). Gender: A less than arbitrary grammatical category. In C. M. R. Hendrick \& M. Miller (Eds.), Papers from the Seventeenth Regional Meeting (pp. 439-449). Chicago: Chicago Linguistic Society.

\section{NOTES}

1. In Italian, the two orders adjective-noun and noun-adjective are both completely grammatical. However, the noun-adjective order is more frequent and is usually regarded as the default (i.e., pragmatically neutral) order. For the present study, selection of adjective primes was restricted to modifiers that are pragmatically felicitous and plausible in prenominal position.

2 . In addition to the two largest word classes (transparent and opaque), a very small number of word types in Italian carry contradictory marking. These include idiosyncratic words such as la mano (a feminine word meaning hand, with masculine marking on the noun but feminine agreement on all modifiers) and a small class of words derived from Greek such as drama or telegramma (masculine words for drama and telegram, with feminine marking on the noun but masculine agreement on all modifiers). The very small class of aberrant or contradictory forms will not be investigated here.

3. As discussed in some detail by Radeau and Morais (1990). Radeau et al. (1989), Grosjean et al. (1994), and Bates et al. (1995), the notion of a "uniqueness point" is not as straightforward for richly inflected languages as it is for English. This is particularly true for 
Italian, where virtually all inflectional morphology is carried on the final vowel-which means that no word form is uniquely identifiable out of context until it is complete. Hence, if uniqueness point measurements are to have any meaning at all, they must pertain to the word root rather than the word form. As described in more detail in Bates et al. (1995), we calculated the uniqueness point using a dictionary method, locating the letter within each word at which the word root or stem was uniquely identifiable. In making these calculations, we also departed from the usual procedures for English by taking lexical stress into account. We did this because lexical stress in Italian interacts with the presence or absence of highly productive word-final derivational morphemes such as the diminutive. For example, the base word bagno has stress on the first syllable, but various derived forms such as bagnino (little bath) have stress on the penultimate syllable. If we take stress into account, then the word root for bagno is uniquely identifiable prior to the final vowel. If we ignore stress, then this word (and most inflectable nouns in Italian) cannot be uniquely identified until much later. Other factors such as syntactic class and gender were not taken into account. As Grosjean et al. and Radeau and colleagues have also noted, the uniqueness point in a gender-marked language may be quite different in context (where the search may be restricted exclusively to masculine or feminine nouns) from that out of context. For all these reasons, we have chosen not to measure reaction time from the uniqueness point in the present study. We include information about the "standard" uniqueness point for two reasons only: (1) to point out that the stimuli do not differ significantly in the point at which a word could be recognized out of context, and (2) to under- score how fast our subjects must be responding when the "functional length" (as opposed to the absolute length) of Italian words is taken into consideration. Any interactions that might occur between contextual variables and the "true" (psychological) uniqueness point must be left to future research.

4. The interval between the offset of each adjective prime and the onset of the target noun was set at zero. However, the current version of PsyScope exacts a small processing cost when two items are compiled online, reflected in the interval between the two words. To determine the exact length of this interval (and its standard deviation), we generated a set of 120 items (equivalent to the individually randomized script for a single subject) and recorded them digitally for visual playback. The distance between the end of the adjective and the beginning of the subsequent noun for each of these 120 items was measured by hand on the SoundEdit 16 system. Results suggested that the mean interval was $13.88 \mathrm{msec}$, with a standard deviation of $0.406 \mathrm{msec}$ and a range of $12.7-14.7 \mathrm{msec}$. This is still a very small interval by the standards of current research on auditory priming. It could have been avoided by hand-compiling all 120 stimuli in a single script. However, because such scripts would take many hours to prepare, this procedure would preclude the randomized assignment of adjectives to nouns for individual subjects, leaving us with the possibility of unintended semantic effects that would pose a greater risk to our design.

(Manuscript received January 19, 1995; revision accepted for publication December 14, 1995.) 